\title{
Vigilancia molecular de la malaria en potenciales reservorios silvestres que viven en una región históricamente endémica de Paraguay
}

\author{
Florencia del Puerto ${ }^{*}$, Diana Pésole ${ }^{2}$, Santiago Molina ${ }^{2}$, Karen Vera $^{2}$, Marcela Arias ${ }^{2}$, Javier Sosa $^{2}$, \\ María Luisa Ortiz ${ }^{2}$, José Fernández ${ }^{2}$, Anastacio Garay ${ }^{2}$
}

${ }^{1}$ Universidad Nacional de Asunción, Instituto de Investigaciones en Ciencias de la Salud, Departamento de Medicina Tropical, San Lorenzo, Paraguay

${ }^{2}$ ITAIPU BINACIONAL, Centro de Investigación de Animales Silvestres de ITAIPU, Hernandarias, Paraguay

Cómo referenciar este artículo/

How to reference this article: del Puerto F, Pésole D, Molina S, Vera K, Arias M, Sosa J, et al. Vigilancia molecular de la malaria en potenciales reservorios silvestres que viven en una región históricamente endémica de Paraguay. Mem. Inst. Investig. Cienc. Salud. 2018; 16(3): 30-34

\section{RES U M E N}

En Paraguay, no se han registrado casos autóctonos de malaria desde el 2011. Se realizó un estudio descriptivo observacional transversal en 6 monos y 23 aves que vivían en una región históricamente endémica de Paraguay para buscar presencia de reservorios silvestres de parásitos plasmodios causantes de la malaria. El ADN se extrajo por el método de Chelex a partir de una gota de sangre en un papel de filtro, y la detección del parásito se realizó mediante la PCR múltiple semianidada. Por este método, no se detectaron parásitos en ninguna de las 29 muestras. Se evaluó el riesgo potencial de circulación selvática de los parásitos que causan la malaria. Teniendo en cuenta la presencia de mosquitos anofelinos vectores en la zona, el hecho de que no se hayan observado casos positivos es un buen indicador teniendo en cuenta que nuestro país fue declarado recientemente como país libre de malaria por la OMS.

Palabras clave: reservorios silvestres, malaria, Paraguay.

\section{Molecular surveillance of malaria in potential wild reservoirs that live in a historically endemic region of Paraguay}

\section{A B S T R A C T}

In Paraguay, autochthonous cases of malaria have not been recorded since 2011. A crosssectional observational descriptive study was conducted in 6 monkeys and 23 birds living in a historically endemic region of Paraguay to identify wild reservoirs of plasmodium parasites that cause malaria. DNA was extracted by the Chelex method from a blood drop in a filter paper, and parasite detection was performed by the seminested multiplex PCR. By this method, parasites were not detected in any of the 29 samples. The risk of potential sylvatic circulation of the parasites causing malaria was evaluated. Considering the presence of anopheline mosquitoes in the area, the fact that we did not find any positive cases is a good indicator as our country was recently certified as a malaria-free country by the WHO.

Keywords: wild reservoirs, malaria, Paraguay

\section{INTRODUCCIÓN}

En la década de 1940, el 90\% de Paraguay era endémico para la malaria, con un $82 \%$ de los casos pertenecientes a los departamentos de Alto Paraná, Caaguazú y Canindeyú. El parásito autóctono que transmite esta enfermedad es el Plasmodium vivax y los vectores primarios y secundarios son las especies de mosquitos Anopheles darlingi y Anopheles 
albitarsis, respectivamente. Debido a las estrategias de control aplicadas, el número de casos disminuyó de manera sostenible de 6853 casos en el 2000 a 1392 casos en el 2003, lo que significó una reducción del $79,7 \%{ }^{(1)}$.

Desde el 2003, la situación epidemiológica continuó exitosamente y la última transmisión autóctona de malaria se informó en 2011. Esta situación hizo que el país sea premiado en el 2012 por la Organización Panamericana de la Salud (OPS) con el primer lugar como "Campeones contra la Malaria en las Américas". Este hecho ubicó a Paraguay entre los seis países en la fase previa a la eliminación de la enfermedad en América Latina (2-4).

Actualmente, el Servicio Nacional de Erradicación del Paludismo (SENEPA) considera los departamentos de Alto Paraná y Caaguazú como áreas de bajo riesgo. Sin embargo, los mosquitos anofelinos todavía están presentes en la zona debido a la existencia de los lagos Yguazú e Itaipú, que podrían ser criaderos de mosquitos vectores. Por lo tanto, no podemos descartar la posibilidad de encontrar reservorios silvestres que puedan generar una transmisión silenciosa de la enfermedad ${ }^{(5)}$.

Aunque los humanos infectados son el principal reservorio de los parásitos plasmodios, teniendo en cuenta que el origen de $P$. falciparum y $P$. vivax en los simios africanos son ejemplos de antiguas zoonosis que pueden continuar hasta ahora para $P$. vivax y muy probablemente para $P$. malariae y $P$. ovale ${ }^{(6)}$, el muestreo puede enfocarse en monos. Otras especies que pueden ser tenidas en cuenta para este tipo de estudios son las aves considerando trabajos previos como uno realizado en Francia, basado en la epidemiología molecular de un grupo de pingüinos africanos que vivían en cautiverio con un registro de infección por Plasmodium y aves de las especies Pica pica y Corvus corone, ambas pertenecientes a la familia Corvidae quienes dieron positivo a la infección ${ }^{(7)}$. Se ha demostrado recientemente que Plasmodium knowlesi, un parásito que infecta principalmente a monos macacos salvajes, puede transmitirse por vectores anofelinos y causar malaria humana en el sudeste de Asia. Esto agrega un quinto parásito a la lista de parásitos de Plasmodium que pueden causar la malaria humana ${ }^{(8)}$ y cuyos reservorios pueden ser primates. En este sentido, hay una falta de estudios centrados en la prevención, el diagnóstico y el tratamiento de la malaria zoonótica.

El Centro de Investigación de Animales Silvestres (CIASI) de la Represa binacional ITAIPÚ (Brasil-Paraguay) en el lado paraguayo, específicamente en el departamento de Alto Paraná, tiene 12 hectáreas de bosque que permiten la vida libre de especies nativas, así como el manejo de especies en peligro de extinción con fines de cría y se encuentra en el departamento de Alto Paraná. Este centro de investigación está ubicado en el área de influencia de la reserva natural y el lago, ambas llamadas ITAIPÚ porque son parte del área comprendida por la represa de Itaipú, una de las represas hidroeléctricas más grandes del mundo, construida sobre el río Paraná, en la frontera entre Brasil y Paraguay. Este lugar es apropiado para acceder a animales que pueden ser potenciales reservorios naturales de parásitos Plasmodium que pueden causar malaria humana. Teniendo en cuenta que la distribución de los vectores en el entorno del lago de Itaipú es uniforme (datos obtenidos de SENEPA), a nuestro entender, no existen estudios basados en la extensión real de la malaria por zoonosis en esta área.

Al realizar el presente proyecto, Paraguay se encontraba bajo vigilancia epidemiológica para malaria. Por lo tanto, comenzar el muestreo con los animales que viven en el CIASI es conveniente para evaluar la circulación de parásitos Plasmodium en un área históricamente endémica y establecer así el precedente para otros estudios de campo. Paraguay se encuentra en vigilancia epidemiológica para malaria. Por lo tanto, comenzar el muestreo con los animales que viven en el CIASI es conveniente para evaluar la circulación de parásitos Plasmodium en un área históricamente endémica y establecer así el precedente para otros estudios de campo para continuar el monitoreo y control de la vida silvestre en el área.

El objetivo de este estudio fue determinar la presencia o ausencia de transmisión vectorial activa de la malaria en aves y monos que viven en cautiverio en una región históricamente endémica. El método molecular propuesto para la detección e identificación de parásitos fue la PCR Múltiple Semianidada (SnM-PCR), que detecta el gen de la subunidad pequeña ribosómica $18 \mathrm{~S}$ y puede identificar las cuatro especies de Plasmodium que transmiten la malaria: $P$. vivax, $P$. falciparum, $P$. ovale y $P$. malariae. 


\section{MATERIALES Y MÉTODOS}

Se realizó un estudio descriptivo de corte transversal en monos y aves que viven en cautiverio en el CIASI, ITAIPU en agosto del 2015. Se incluyeron solo a aquellas especies que vivieron allí durante al menos cinco años antes del 2011, que es el año en que se informó el último caso autóctono de malaria. Con estos criterios, se tomaron muestras de sangre de un total de 29 animales: Sapajus cay (3), Allouata caraya (3), Amazona aestiva (3), Pipile grayi (1), Bubo virginianus (1), Ara chloropterus (4), Crax fasciolata (6), Caracara plancus (2), Chauna torquata (3), Cariama cristata (1) y Cairina moschata (2).

La sangre fue tomada por médicos veterinarios del CIASI, siguiendo los protocolos de Bailey et al., 2008 (9) y Campbell et al., 1994 (10), en una cantidad mínima para colocar una gota en un papel de filtro. Las muestras fueron luego secadas y transportadas a temperatura ambiente al Instituto de Investigaciones en Ciencias de la Salud, Asunción, Paraguay. Una vez en el laboratorio, las muestras se almacenaron a $-20^{\circ} \mathrm{C}$ para una posterior extracción del ADN.

El ADN se extrajo mediante el Método Chelex previamente descrito por Rubio et al,. $1999^{(11)}$ y el método SnM-PCR se realizó de acuerdo con el protocolo descrito en Thuy et al., $2011^{(12)}$, con la única modificación que no se usó el cebador HUF en la PCR1, debido a que este es un cebador para amplificar ADN humano como control positivo de reacción.

Los productos de PCR se tiñeron con bromuro de etidio y se visualizaron en geles de agarosa al $2 \%$. Los tamaños fueron corroborados con mediante un marcador de peso molecular de $100 \mathrm{pb}$.

Como control positive se usó ADN genómico comercial de Plasmodium falciparum RO, MRA-200G., obtenido a través del MR4 como parte del BEI Resources Repository, NIAID, NIH.

El protocolo de investigación fue aceptado por los Comités Ético y Científico del Instituto de Investigaciones en Ciencias de la Salud (IICS-UNA), Asunción, Paraguay, bajo el código P13 / 2015 con el nombre de: Riesgo potencial de transmisión silenciosa de paludismo en reservorios silvestres que habitan un área históricamente endémica. Los autores declaran no tener ningún conflicto de intereses y este estudio se llevó a cabo con fondos propios del IICS-UNA.

\section{RESULTADOS}

Tabla 1. No se detectaron parásitos en ninguna de las 29 muestras

\begin{tabular}{llcl} 
Especies & N & SnM-PCR & \\
\hline Sapajus cay & 3 & - & Primates \\
Allouata caraya & 3 & - & Primates \\
Amazona estiva & 3 & - & Aves \\
Pipile grayi & 1 & - & Aves \\
Bubo virginiamus & 1 & - & Aves \\
Ara chloropternis & 4 & - & Aves \\
Crax fasciolata & 6 & - & Aves \\
Caracara plancus & 2 & - & Aves \\
Chanina torquata & 3 & - & Aves \\
Cariama cristata & 1 & - & Aves \\
Cairina moschata & 2 & - & Aves \\
\hline Total & 29 & & \\
\hline
\end{tabular}




\section{DISCUSIÓN}

Al momento de realizar este estudio, Paraguay se encontraba en el proceso de eliminación de la malaria y, por lo tanto, se proyectaba a obtener la certificación de país libre de la enfermedad en un futuro cercano, lo que fue posible recientemente en el $2018^{(13)}$. En esa fase se requería de vigilancia en varios frentes, en este caso en una población de animales salvajes que puedan servir como reservorios naturales para los parásitos Plasmodium.

En Paraguay, la mayoría de las áreas históricamente consideradas endémicas para la malaria se están utilizando actualmente para el cultivo masivo de trigo y soja, y por lo tanto, hay muy pocas áreas verdes que pueden ser habitadas por animales salvajes con potencial para ser reservorios silvestres. La reserva de la represa hidroeléctrica de ITAIPÚ es una de las pocas grandes áreas verdes en esta área históricamente endémica. Aunque hay animales salvajes que viven en la zona, el costo logístico para capturarlos y tomarles la muestra es alto. En este sentido, dada la presencia del vector en el área, el enfoque más factible fue acceder a los animales que viven en cautiverio en el Centro de Investigación de Animales Silvestres (CIASI) de ITAIPÚ, que también se encuentra en el área de influencia de la represa. Si hubiéramos encontrado algún animal positivo a los parásitos Plasmodium, hubiese ameritado ahondar el estudio en animales salvajes del área.

Desde el punto de vista molecular, si bien la técnica de SnM-PCR empleada, en principio fue estandarizada para detectar plasmodios en humanos, lo que queda pendiente y de hecho estamos trabajando en ello, es el diseño de cebadores propios de las especies sujetos del presente estudio. La idea es contar con controles positivos internos de amplificación equivalentes a la función que realiza el cebador HUF en la SnM-PCR de Thuy-Huong Ta Tang et al., 2011. No obstante, como el proceso de almacenamiento de muestra y extracción de ADN realizado (muestras de sangre en papel de filtro y extracción con Chelex 100, respectivamente) es en principio el mismo realizado para detección de plasmodios en humanos $^{(11,14)}$, nos lleva a asumir que aunque no hayamos contado con controles positivos internos de reacción, el hecho de haber obtenido amplificación del control positivo (ADN genómico de $P$. falciparum) de manera exitosa, demuestra que la reacción en sí no tuvo mayores inconvenientes.

Es más, la calidad de las muestras es óptima, prueba de su integridad es que las mismas muestras de aves han sido utilizadas para la identificación del sexo de las mismas por métodos moleculares y fue publicado en del Puerto et al., $2017^{(15)}$.

Hasta donde sabemos, es la primera vez que se realiza este tipo de estudio en el país aunando esfuerzos para la vigilancia activa de la malaria. Dado que los animales estudiados viven en el área de influencia de la reserva natural de la represa hidroeléctrica de ITAIPÚ, donde todavía circulan vectores anofelinos, el hecho de que no hayamos encontrado casos positivos, que puedan haber indicado una circulación silenciosa, es prometedora y un buen indicador más en estos momentos donde en junio del 2018, Paraguay logró la certificación de país libre de malaria.

Fuente de Financiación: Recursos propios del Departamento de Medicina Tropical, IICSUNA.

\section{REFERENCIAS BIBLIOGRÁFICAS}

1. Manual de Diagnóstico microscópico de la Malaria. 2011. Programa Nacional de Control del Paludismo. SENEPA-MSP y BS. Publicación auspiciada por la OPS/OMS 1$112 \mathrm{pp}$.

2. ABC color digital. 2012. Paraguay "Campeones contra la Malaria" http://www.abc.com.py/nacionales/paragua y-obtiene-premio-campeones-contra-lamalaria-475774.html. Última actualización el viernes, 28 de febrero de 2014 8:04

3. World Malaria Report 2012. WHO, Chapter 8: Changes in malaria incidence and mortality, Region of Americas. WHO Press, World Health Organization, 20 Avenue

Appia, 1211 Geneva 27, Switzerland. 78-79 p.

4. Departamento prensa del Ministerio de Salud Pública y Bienestar Social. 2009. Malaria en Paraguay: se redujo casi el $100 \%$ de número de casos, en diez años. http://www.mspbs.gov.py/v2/4954-Malariaen-Paraguay-SE-REDUJO-CASI-EL-100-DENUMERO-DE-CASOS-EN-DIEZ-AOS. Última actualización el viernes, 28 de febrero de 2014 8:04

5. Malaria, Paludismo o Akanunduro'y. Servicio Nacional de Erradicación del Paludismo SENEPA.

http://senepa.gov.py/images/stories/rotafoli 
o_malaria.pdf. Última actualización el Lunes, 05 de Noviembre de 2012 12:02

6. Ramasamy R. Zoonotic malaria - global overview and research and policy needs. Front PublicHealth. 18;2:123 doi: 10.3389/fpubh.2014.00123

7. Leclerc A, Chavatte JM, Landau I, Snounou G, Petit T. 2014. Morphologic and molecular study of hemoparasites in wild corvids and evidence of sequence identity with Plasmodium DNA detected in captive blackfooted penguins (Spheniscusdemersus). J Zoo Wildl Med. Sep; 45(3):577-88.

8. Singh B, Kim Sung L, Matusop A, Radhakrishnan A, Shamsul SS, et al. 2004. A large focus of naturally acquired Plasmodium knowlesi infections in human beings. Lancet 363: 1017-24.

9. Bailey, T. Capture and Handling. In: Samour, J. Avian Medicine. 2da ed. Canada: Elsevier; 2008. p. 1-2

10. Campbell, T. Hematology. In: Ritchie, B; Harrison, G; Harrison, L. Avian Medicine: Principles and application. Wingers Publishing Inc.;1994. p. 176- 198

11. Rubio JM, Benito A, Berzosa PJ, Roche J, Puente $S$, Subirats $M$, López-Vélez $R$, García L, Alvar J. 1999. Usefulness of seminested multiplex PCR in surveillance of imported malaria in Spain. J ClinMicrobiol. Oct;37(10):3260-4.
12. Thuy-Huong Ta Tang. Detección e identificación de plasmodios mediante PCR múltiple semianidada. En: Luis A. Merino y Gustavo Giusiano. Manual de métodos moleculares para estudios microbiológicos. Buenos Aires: Asociación Argentina de Microbiología; 2011. 109-10

13. OMS certifica que Paraguay está libre de Malaria. 11 de junio de 2018. https://www.paho.org/hq/index.php?optio $\mathrm{n}=\mathrm{com}$ _content\&view $=$ article\&id $=144$ $28 \% 3$ Awho-certifies-paraguay-malariafree- $\&$ catid $=740 \% 3$ Apressreleases\&Itemid $=1926 \& l a n g=e s \quad$ Última actualización jueves, 28 de junio de 2018, 17:25 pm

14. Barrios ED, Russomando G, Puerto FD. 2016. Absence of asymptomatic cases of malaria in a historically endemic indigenous locality of the Department of Caaguazú, Paraguay: moving toward elimination. Rev Soc Bras Med Trop 49(5):637-40

15. del Puerto F, Pésole $D$, Molina $S$, Vera $K$, Arias M, Sosa J, et al. Identificación molecular del sexo en 9 especies de aves del Centro de Investigación en Animales Silvestres de la hidroelétrica de ITAIPU, lado paraguayo. Mem Inst Investig Cienc Salud 2017; 15(3):89-92. 